\title{
Activation of violaxanthin cycle in darkness is a common response to different abiotic stresses: a case study in Pelvetia canaliculata
}

\author{
Beatriz Fernández-Marín*, Fátima Míguez, José María Becerril and José Ignacio García-Plazaola
}

\begin{abstract}
Background: In the violaxanthin ( $)$ cycle, $V$ is de-epoxidized to zeaxanthin (Z) when strong light or light combined with other stressors lead to an overexcitation of photosystems. However, plants can also suffer stress in darkness and recent reports have shown that dehydration triggers V-de-epoxidation in the absence of light. In this study, we used the highly stress-tolerant brown alga Pelvetia canaliculata as a model organism, due to its lack of lutein and its non-photochemical quenching independent of the transthylakoidal- $\Delta \mathrm{pH}$, to study the triggering of the $\mathrm{V}$-cycle in darkness induced by abiotic stressors.

Results: We have shown that besides desiccation, other factors such as immersion, anoxia and high temperature also induced V-de-epoxidation in darkness. This process was reversible once the treatments had ceased (with the exception of heat, which caused lethal damage). Irrespective of the stressor applied, the resulting de-epoxidised xanthophylls correlated with a decrease in Fv/Fm, suggesting a common function in the down-regulation of photosynthetical efficiency. The implication of the redox-state of the plastoquinone-pool and of the differential activity of V-cycle enzymes on V-de-epoxidation in darkness was also examined. Current results suggest that both violaxanthin de-epoxidase (VDE) and zeaxanthin-epoxidase (ZE) have a basal constitutive activity even in darkness, being ZE inhibited under stress. This inhibition leads to $Z$ accumulation.

Conclusion: This study demonstrates that $\mathrm{V}$-cycle activity is triggered by several abiotic stressors even when they occur in an absolute absence of light, leading to a decrease in Fv/Fm. This finding provides new insights into an understanding of the regulation mechanism of the $\mathrm{V}$-cycle and of its ecophysiological roles.
\end{abstract}

\section{Background}

The violaxanthin (V) cycle, described in plants and green and brown algae (Müller et al. 2001), consists of the light-driven de-epoxidation of $\mathrm{V}$ to form antheraxanthin (A) and then zeaxanthin ( $\mathrm{Z})$, and the epoxidation of $\mathrm{Z}$ back to $\mathrm{V}$ in darkness. The first reaction is catalyzed by violaxanthin deepoxidase (VDE), an enzyme that, for its activation, requires the acidic $\mathrm{pH}$ that results from photosynthetic proton pumping [1]. De-epoxidation of $\mathrm{V}$ to $\mathrm{A}+\mathrm{Z}$ enhances and modulates the rate of thermal dissipation of the excess of excitation energy [2]. The biophysical mechanism by which this process occurs is still a matter of debate [3-7]. This process can be monitored by the decrease in chlorophyll $a$ fluorescence yield, the

\footnotetext{
* Correspondence: beatriz.fernandezm@ehu.es

Department of Plant Physiology and Ecology, University of the Basque Country (UPV/EHU), Apdo 644, 48080 Bilbao, Spain
}

so-called non-photochemical quenching (NPQ). Although light has been considered to be a requisite for the activation of VDE in all organisms studied until now, studies performed with non-natural systems have suggested that artificial induction of $\mathrm{V}$ de-epoxidation in darkness may be possible. In isolated thylakoids of lettuce, the dark-induction of the Z-dependent quenching of chlorophyll fluorescence mediated by external ATP supplies has been shown [8]. In Arabidopsis mutants lacking a chloroplast NAD Kinase, an accumulation of high levels of $\mathrm{Z}$ was observed in darkness [9]. More recently, $\mathrm{Z}$ accumulation in darkness has been observed in natural, cold-acclimated oak leaves [10] while several papers have confirmed that the de-epoxidation of $\mathrm{V}$ can be induced under natural conditions by desiccation $[11,12]$, irrespective of the illumination of photosynthetic tissues.

\section{(Ciomed Central}


In green algae and plants, apart from the presence of $\mathrm{A}+\mathrm{Z}$, a trans-thylakoidal proton gradient $(\Delta \mathrm{pH})$ is required to obtain the highest NPQ [2]. In brown algae, however, the generation of NPQ depends exclusively on the operation of the $\mathrm{V}$-cycle, whereas acidic $\mathrm{pH}$ is only required to activate VDE [13]. The direct dependence of NPQ on Z and the lack of lutein, another carotenoid that contributes to NPQ [14], greatly facilitate the study of the functions and operation of the $\mathrm{V}$-cycle, becoming brown algae excellent model species in such studies.

Among brown seaweeds, Pelvetia canaliculata is one of the most stress-tolerant species. It forms the highest band on the shore above Fucus spiralis and is very desiccationtolerant, surviving for more than 7 days out of water [15], when it can lose up to $96 \%$ of its water content [16]. The unique desiccation tolerance ability of this species seems to rely on a symbiosis with the endophytic fungus: $\mathrm{Myco-}$ sphaerella acophylli (Ascomycetes) [17]. But besides dehydration, the emersion of intertidal algae is associated with other stressors such as high temperatures that can damage their tissues [18]. Strong light is also a stress factor that intertidal algae have to deal with. A very recent paper has reported that $P$. canaliculata acclimates very quickly to high radiations based on an efficient carotenoids composition [19]. Furthermore, the high V-cycle pool size of $P$. canaliculata seems to be associated with its strong tolerance to abiotic stresses [20].

Since an increasing number of evidences support the dark operation of $\mathrm{V}$-cycle under some environmental conditions, but its physiological role and regulation remains unknown, $P$. canaliculata has been used as a model species in this paper to provide further insights into this mechanism. Specifically, we have determined whether environmental factors, other than light, may trigger the activation of the $\mathrm{V}$-cycle. Three environmental factors that this highly stress-tolerant species can eventually encounter during its lifespan have been studied in the absence of light: desiccation that occurs when thalli are exposed to air for a long time, and supraoptimal temperature and anoxia that occur at low tide when oxygen is depleted from the small intertidal pools. The second aim of this work was to verify whether the pool of $A+Z$, formed after VDE activation in darkness, is involved in the regulation of photochemical efficiency in the same way as the pool of $\mathrm{A}+\mathrm{Z}$, generated by high irradiance. This paper not only aims to gain an understanding of this protective mechanism, but also to look more deeply into the functioning and environmental role of the V-cycle.

\section{Methods}

Plant material

Pelvetia canaliculata (L.) Decn. et Thur. (also called channelled wrack) is a brown seaweed of the Fucaceae family distributed on the cold shores of the northern hemisphere. Adult thalli were collected from the Northern coast of Spain. Before any analysis, samples were covered with a tissue soaked in seawater and kept in darkness at room temperature and 100\% Relative Humidity $(\mathrm{RH})$, during $12 \mathrm{~h}$, to allow V-cycle relaxation. For all the experiments, the last apical bifurcation of the thalli was used, since this is the most active part and that which is most directly exposed to desiccation.

\section{Experimental treatments}

The thalli collected as previously described were exposed to different experimental treatments, as follows:

\section{- Illumination}

Samples over a tissue moistened with seawater were directly exposed to sunlight (Photon Flux Density -PFDof $1500 \mu \mathrm{mol} \mathrm{m}^{-2} \mathrm{~s}^{-1}$ ), for 15 or $60 \mathrm{~min}$, and continuously remoistened with seawater to avoid desiccation. After light treatment, the thalli were maintained wet in darkness (to allow V-cycle re-epoxidation) for another $60 \mathrm{~min}$.

\section{- Desiccation}

Samples were incubated in the dark for $24 \mathrm{~h}$ in glass hermetic chambers, containing a $\mathrm{NaCl}$ saturated solution (75\% Relative Humidity - $\mathrm{RH}-$ ). Rehydration was begun by directly spilling seawater over the thalli. Samples were then kept over a tissue wet with seawater and at $100 \% \mathrm{RH}$ to allow recovery.

\section{- Desiccation of pre-illuminated thalli}

Bifurcated thalli, of which one of the branches was covered with aluminium foil, were exposed to sunlight for $15 \mathrm{~min}$ and then put into a hermetic chamber to start desiccation treatment as previously described.

\section{- High temperature}

Thalli were incubated in darkness at $32^{\circ} \mathrm{C}$ during $23 \mathrm{~h}$, and then transferred to $17^{\circ} \mathrm{C}$ for $29 \mathrm{~h}$ further as recovery. To avoid desiccation, thalli were placed over a tissue wet with seawater and in a controlled atmosphere at 100\% $\mathrm{RH}$. As a control a second set of samples was maintained in darkness at $17^{\circ} \mathrm{C}$ and $100 \% \mathrm{RH}$.

\section{- Immersion}

Thalli were submerged in darkness in seawater in $2 \mathrm{~mL}$ volume vials for 10 and $24 \mathrm{~h}$.

\section{- Anaerobiosis}

Thalli were incubated in darkness during 1,6 and $17 \mathrm{~h}$, in closed vacutainers in which the air was replaced by $\mathrm{N}_{2}$ gas. For controls, some samples were kept in vacutainers containing air. After the treatment, the samples were incubated in open vacutainers during $4 \mathrm{~h}$ to allow reoxygenation of tissues. During the incubations, all samples remained covered with a seawater-moistened tissue to avoid dehydration.

\section{Metabolic inhibitors}

Since the acidification of lumen generated by the proton pumping of the ETC carriers in parallel to electron 
transport is required for the de-epoxidation of $\mathrm{V}$, a set of inhibitors affecting either the activity of $\mathrm{V}$-cycle enzymes, the transthylakoidal $\mathrm{pH}$ or the redox-state of the PQ pool, were infiltrated in samples that were then desiccated in darkness (as described above). Thalli were infiltrated with different concentrations of metabolic inhibitors dissolved in seawater with $1 \%$ ethanol to facilitate the dilution. For the infiltration, thalli were placed into vacutainers containing $5 \mathrm{~mL}$ of inhibitor solutions. By removing the air with a $50 \mathrm{~mL}$ syringe 5 times, a vacuum was created. After infiltration, samples were incubated into the solution for $1 \mathrm{~h}$. Controls were treated with seawater and 1\% ethanol following the same infiltration protocol. After inhibitor treatments, samples were either desiccated as described above or maintained hydrated. The following inhibitors (all from SigmaAldrich, Spain) were used:

- Dithiothreitol (DTT)

inhibits the enzyme VDE [21]. It was applied at a concentration of $5 \mathrm{mM}$.

\section{- Salicyl-adoxime (SA)}

inhibits the ZE activity [22]. It was applied at a concentration of $5 \mathrm{mM}$.

\section{- Ammonium chloride $\left(\mathrm{NH}_{4} \mathrm{Cl}\right)$}

uncouples the transthylakoidal- $\Delta \mathrm{pH}$ [13] by sequestering $\mathrm{H}+$ in the lumen. It was applied at a concentration of $100 \mathrm{mM}$.

\section{- 2,5-Dibromo-6-isopropyl-3-methyl-1,4-benzoquinone (DBMIB)}

avoids the oxidation of PQ by residing at the $\mathrm{Q}_{0}$ site of the cytochrome b6f complex [23]. It was applied at a concentration of $25 \mu \mathrm{M}$.

\section{- Dichlorophenyl dimethylurea (DCMU)}

avoids the reduction of PQ by blocking the electron flow from PS II [24]. It was applied at a concentration of $10 \mu \mathrm{M}$.

\section{- n-Propyl-gallate (n-PG)}

blocks the chlororespiratory oxidation of PQ mediated by the enzyme plastid terminal oxidase (PTOX) [25]. It was applied at a concentration of $1 \mathrm{mM}$.

\section{- Far red (FR)}

a modulated light of $\lambda>700 \mathrm{~nm}$ provided by an halogen lamp with a FR filter was applied during all the desiccation of FR-treated thalli to maintain the PQ oxidized due to the induction of the PS I.

\section{Chlorophyll $a$ fluorescence analysis}

Fluorescence of chlorophyll $a$ was measured with an imaging fluorometer (Handy FluorCam, P.S.I., Brno, Czech Republic, http://www.psi.cz), as described in [26]. Images of photochemical efficiency were captured before and immediately after each treatment in the thalli that were previously dark-adapted for at least $5 \mathrm{~min}$. Fluorescence was detected by a high-sensitivity charge coupled device camera that produced images of 12-bit resolution. The instrument is driven by the FluorCam software package (FluorCam 7). First, images of the dark-adapted fluorescence level, $\mathrm{F}_{0}$, were determined using non-actinic measuring flashes provided by super-bright light emitting diodes (LEDs). Next, an 800 ms duration pulse of saturating light radiation $\left(2000 \mu \mathrm{mol}\right.$ photon $\left.\mathrm{m}^{-2} \mathrm{~s}^{-1}\right)$ generated by a halogen lamp was given to measure the maximum fluorescence level, Fm. The Maximal Photochemical Efficiency of Photosystem II (Fv/Fm) was calculated as (Fm$\mathrm{F}_{0}$ )/Fm. Pixel value images of the $\mathrm{Fv} / \mathrm{Fm}$ were displayed as a false colour code ranging from blue (0.1) through green and yellow to red (0.9). The Fv/Fm was calculated for each pixel and then averaged for the total area of each sample. The NPQ was not measured because volume contractions associated with desiccation impedes the obtention of comparable Fm (reference Fm') and Fm' (actual Fm'). Thus, the decrease in Fv/Fm associated with sustained thermal dissipation was used as a proxy of NPQ.

\section{Chromatographic analysis}

For pigment analysis, samples were immediately frozen in liquid $\mathrm{N}_{2}$ and stored at $-80^{\circ} \mathrm{C}$ until use. Frozen samples were homogenized with a Tissue Tearor Homogenizer (Model 395, Dremel, Mexico) in pure acetone solution buffered with $\mathrm{CaCO}_{3}$. The extracts were centrifuged at $16100 \mathrm{~g}$ for $20 \mathrm{~min}$, and supernatants were filtered with $0.2 \mathrm{~mm}$ PTFE filters (Teknokroma, Spain). Pigment separation was performed by HPLC with a reverse phase C18 column (Waters Spherisorb ODS1, $4.6 \times 250 \mathrm{~mm}$, Massachusetts, USA), following the method of [27], with the modifications described in [28]. During processing in the HPLC, samples were maintained at $4^{\circ} \mathrm{C}$ in a refrigerated compartment. Identification and quantification was carried out with a photodiode array (PDA) detector. Retention times and conversion factors for pigments were the same as described by $[27,28]$ The relative de-epoxidation state of the xanthophyll cycle pigments was estimated by the ratio $(\mathrm{A}+\mathrm{Z}) /(\mathrm{V}+\mathrm{A}+\mathrm{Z})$ and represented by the abbreviation AZ/VAZ.

\section{Statistics}

A one-way ANOVA was used to test for differences in $\mathrm{AZ} / \mathrm{VAZ}$ and $\mathrm{Fv} / \mathrm{Fm}$ values in response to light, desiccation, immersion and anoxia treatments, after Chochran's test to check for the homogeneity of variances. A Duncan post-hoc test was performed to discriminate among different times and treatments. When necessary, data were logtransformed. The Mann-Whitney $U$ test was used for non-normal data. A linear regression was used to analyse the relationship between AZ/VAZ and Fv/Fm. Calculated $p$-values, coefficients and regression lines are indicated on 
the figures whenever significant at $\alpha=0.05$. All analyses were performed using the SPSS 17.0 statistical package.

\section{Results}

\section{V-cycle operation upon illumination in Pelvetia} canaliculata

The usual operation of the violaxanthin cycle (V-cycle) induced by light was ascertained for $P$. canaliculata. When exposed to sunlight, violaxanthin (V) was quickly de-epoxidised to antheraxanthin (A) and zeaxanthin (Z), this being $60 \%$ the fraction of the VAZ pool converted to $A+Z$ in $30 \mathrm{~min}$ (Figure 1). During the exposure to darkness, $\mathrm{Z}$ and $\mathrm{A}$ were slowly re-epoxidised back to $\mathrm{V}$, closing the cycle. Throughout the entire process, Fv/Fm followed an inverse pattern to AZ/VAZ, reaching the maximum value when AZ/VAZ was almost zero. Both parameters (Fv/Fm and AZ/VAZ) were negatively correlated (see insert in Figure 1).

\section{V-cycle and dehydration}

After verifying its regular activity under light, the Vcycle operation of $P$. canaliculata was analyzed in the absence of light during a dehydration-rehydration treatment (Figure 2), as described in the materials and methods section. During dehydration, and despite the darkness, $\mathrm{V}$ was de-epoxidised into $\mathrm{A}+\mathrm{Z}$, and the

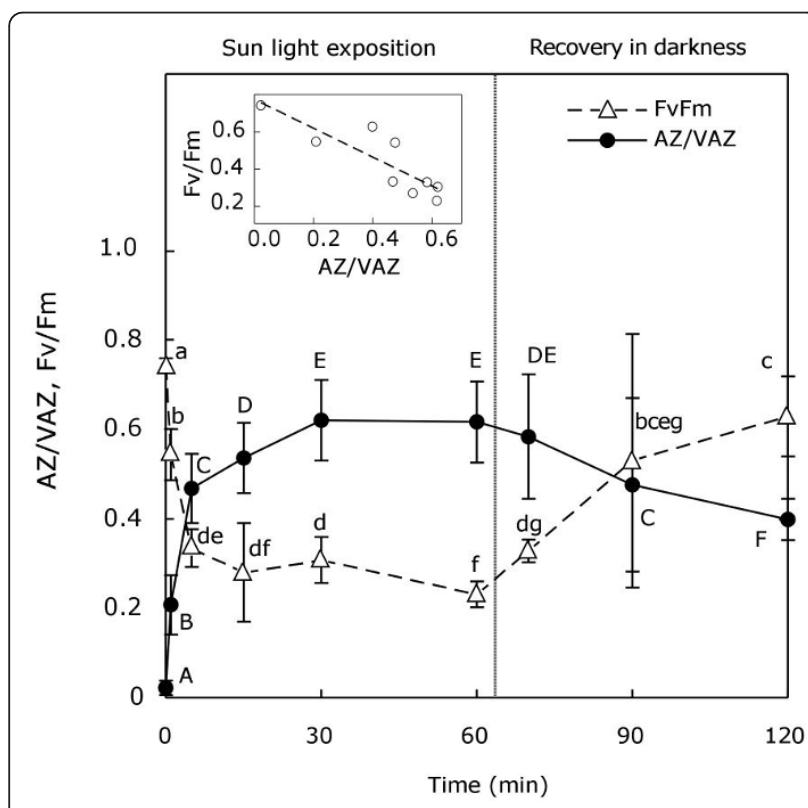

Figure 1 De-epoxidation index of V-cycle (close cyrcles) and variations in Fv/Fm (open triangles) during light-darkness treatment. Each point represents the mean \pm SE $(n=5)$. Capital letters above circles show significant differences in the AZNAZ among times $(P<0.05)$. Small letters above triangles represent significant differences in the $\mathrm{Fv} / \mathrm{Fm}$ among times $(P<0.05)$. Correlation between AZNAZ and Fv/Fm is shown in the inset (Pearson's correlation coefficient; $r=0.74$ ).

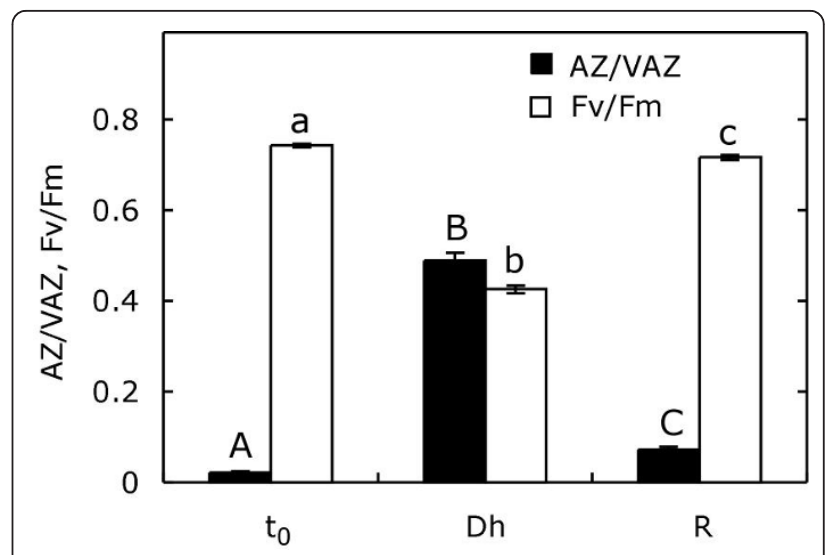

Figure 2 De-epoxidation index of V-cycle and variations in Fv/ Fm during a dehydration-rehydration treatment in darkness. Dehydration (Dh) was performed at 75\% RH for $24 \mathrm{~h}$. V-cycle deepoxidation index is represented by closed bars and Fv/Fm by open bars. Each bar represents the mean \pm SE $(n=5)$. Letters above bars indicate significant differences for AZNAZ ( $A, B$ and $C$ ) and for Fv/ Fm $(a, b, c)$ along treatment $(P<0.05)$.

reverse reaction occurred after rehydration with seawater. As observed during the light experiment (Figure 1), the lowest $\mathrm{Fv} / \mathrm{Fm}$ value was concomitant with the highest AZ/VAZ level (Figure 2).

To verify whether $\mathrm{A}+\mathrm{Z}$ produced during dehydration may have different roles than that synthesised under light conditions, a new test was performed to compare their influence on Fv/Fm. For this purpose, samples of $P$. canaliculata were exposed to sunlight for 15 minutes, while half of each thallus was protected from light (with aluminium foil). After this light/darkness pre-treatment, all samples were dehydrated in the absence of light, as described previously. The illumination of the thalli increased the AZ/VAZ ratio to $0.53 \pm 0.03$. After dehydration, this index remained constant $(0.50 \pm 0.03)$ in pre-illuminated samples (Figure $3 \mathrm{~b}$, open bars) and increased to the same extent $(0.46 \pm 0.05)$ in non preilluminated thalli (Figure 3b, close bars). It should be pointed out that this $\mathrm{A}+\mathrm{Z}$ was induced by light in the former, whereas it was generated in darkness during dehydration in the latter. The $\mathrm{Fv} / \mathrm{Fm}$ reflected the changes on the de-epoxidation index of the $\mathrm{V}$-cycle (Figure 3c): at the beginning of the experiment, Fv/Fm was significantly higher in dark-adapted samples than in pre-illuminated thalli, but during dehydration it decreased considerably, reaching the same value as in pre-illuminated thalli (Figure 3a,c).

\section{Supraoptimal temperature}

The effect of high temperature on the $\mathrm{V}$-cycle was analyzed in thalli incubated in darkness at $32^{\circ} \mathrm{C}$ (Figure 4). After $6 \mathrm{~h}$ of incubation, heat-treated samples showed a significant increase in the AZ/VAZ ratio, which further 


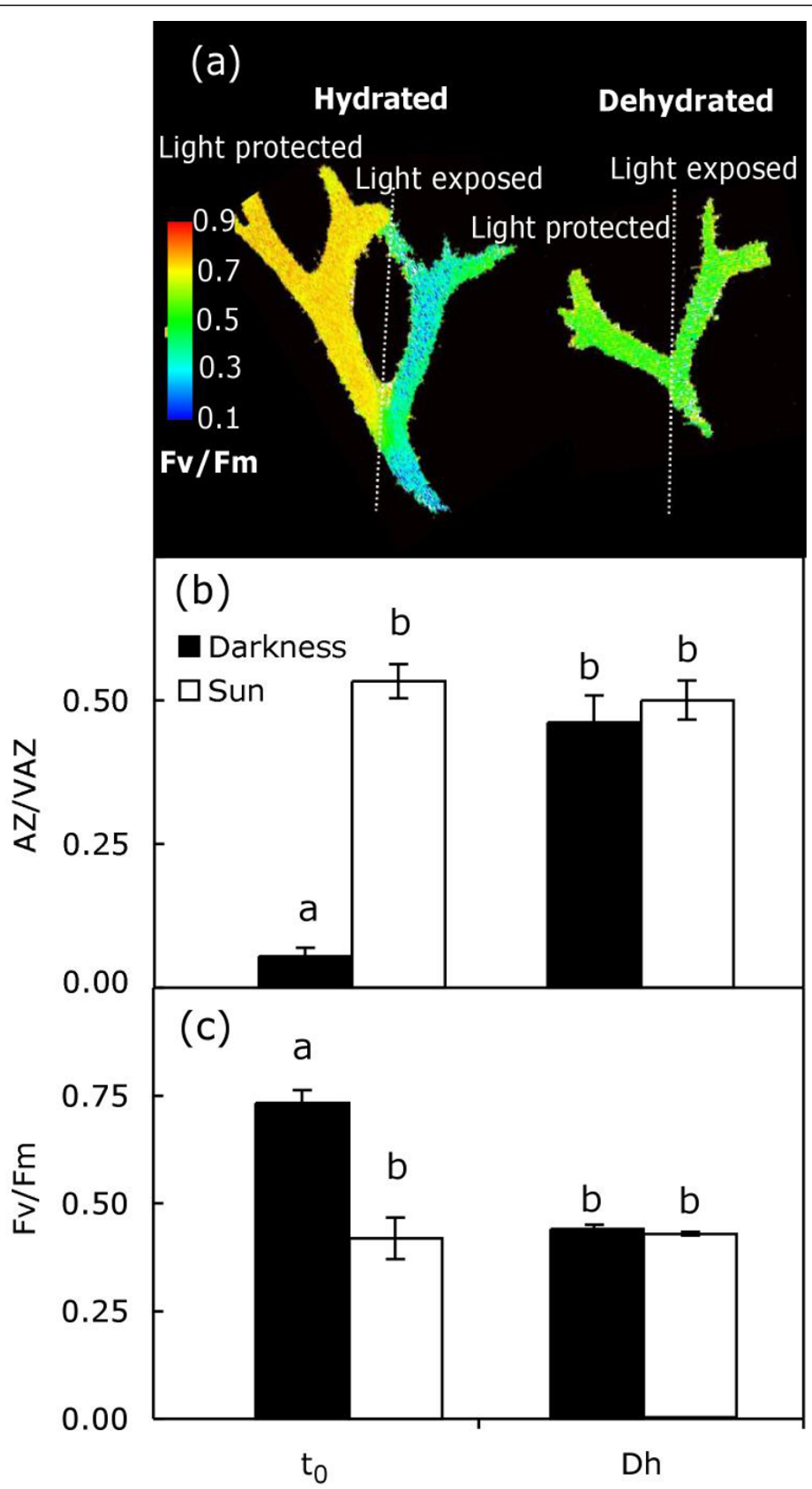

Figure 3 De-epoxidation index of V-cycle and Fv/Fm variations during dark-dehydration after light or darkness pre-treatment. In (a) it is shown a fluorescence imaging of thalli before (left) and after dehydration (right). Before dehydration, the right branch of each thallus had been exposed to sun, and the left one had been maintained in darkness. The de-epoxidation index of the V-cycle (b) and Fv/Fm (c) are shown before $\left(\mathrm{t}_{0}\right)$ and after dark-dehydration (Dh) of pre-darkened (closed bars) and pre-illuminated samples (open bars). Each bar represents the mean \pm SE $(n=5)$. Letters above bars indicate significant differences among treatments $(P<0.05)$. 


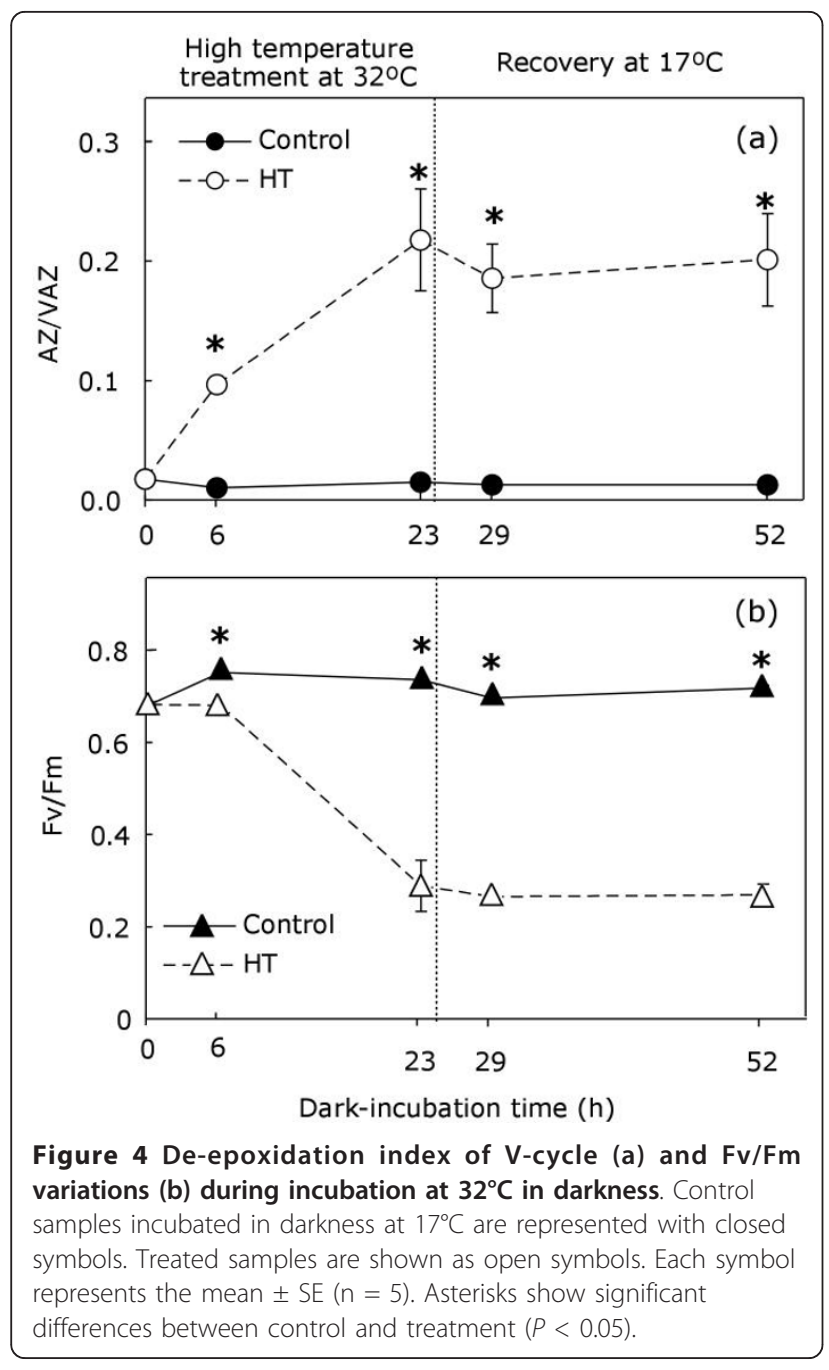

increased at $23 \mathrm{~h}$ (Figure 4a). In parallel, the Fv/Fm decreased throughout the incubation until it reached values of around 0.2 (Figure $4 \mathrm{~b}$ ). In contrast to that observed for desiccation (Figure 2), the return of treated samples to control conditions $\left(17^{\circ} \mathrm{C}\right)$ did not reverse the initial values of $\mathrm{AZ} / \mathrm{VAZ}$ nor of $\mathrm{Fv} / \mathrm{Fm}$.

\section{V-cycle and anoxia}

Being an intertidal, desiccation-tolerant alga that grows high up on the shore, it has been demonstrated that long, frequent immersions are detrimental for P. canaliculata. The activity of the V-cycle was monitored during a long immersion of $24 \mathrm{~h}$ in darkness (Figure 5). Surprisingly, despite the absence of light, $\mathrm{V}$ was de-epoxidised to $\mathrm{A}$ and $\mathrm{Z}$ after $10 \mathrm{~h}$ of immersion. After disregarding the possibility of any changes in the $\mathrm{pH}$ of the water (data not shown) due to respiration, as the factor that induced V-cycle de-epoxidation during immersion, the effects of anoxic conditions were tested separately.

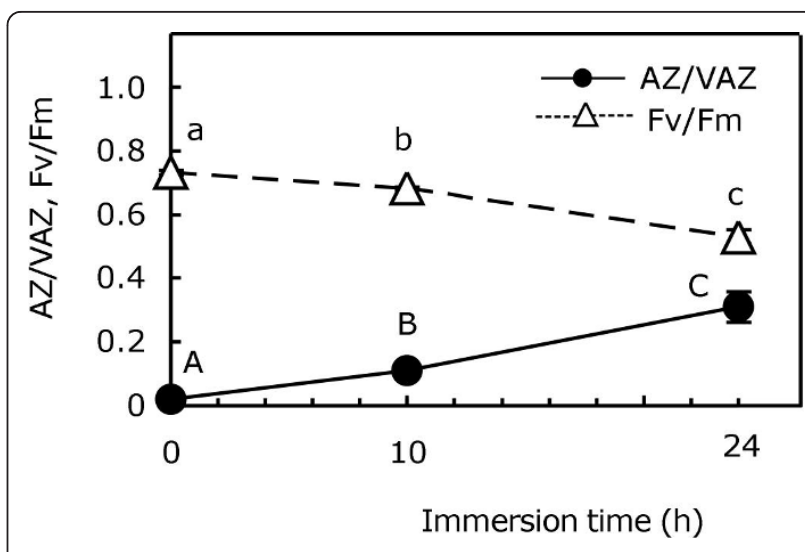

Figure 5 De-epoxidation index of V-cycle (close circles) and Fv/ $\mathrm{Fm}$ variations (open triangles) during immersion into seawater in darkness. Each symbol represents the mean $\pm \operatorname{SE}(n=5)$. Letters above bars indicate significant differences for $\operatorname{AZNAZ}(\mathrm{A}, \mathrm{B}$ and $\mathrm{C})$ and for $\mathrm{Fv} / \mathrm{Fm}(\mathrm{a}, \mathrm{b}, \mathrm{c})$ among immersion times $(P<0.05)$.

Samples covered with a tissue moistened with seawater were dark-incubated in sealed vials within a $\mathrm{N}_{2}$ atm (anoxic atmosphere), while controls were incubated in the same way, but within an air atmosphere. Incubation in anoxia induced the de-epoxidation of a V-cycle (Figure 6a). Under these conditions, one hour was enough to induce a slight, but significant, increase in the AZ/VAZ ratio. After $6 \mathrm{~h}$, it became 12-fold higher than in the controls and after $17 \mathrm{~h}$ of incubation, AZ/ VAZ increased to values in the range of those reached under high irradiance (compare Figure 6a and Figure 1). In a parallel manner to the increases in AZ/VAZ, Fv/Fm underwent a progressive decrease that after $17 \mathrm{~h}$ under a $\mathrm{N}_{2}$-atm, was significantly different from what occurred in the control (Figure 6b). After $17 \mathrm{~h}$ of incubation, treated samples were transferred to an air atmosphere to allow the re-oxygenation of thalli. After $4 \mathrm{~h}$ in an air atmosphere, the de-epoxidation of the $\mathrm{V}$-cycle was reverted, and AZ/VAZ decreased to values below 0.2 (Figure 6a), while Fv/Fm recovered considerably, although it remained below the control value.

\section{Fv/Fm and V-cycle}

The relationship between AZ/VAZ and Fv/Fm was tested for all treatments (high light, dark-dehydration, dark-immersion, dark-anoxia and dark-incubation at high temperature) to verify whether $\mathrm{A}+\mathrm{Z}$ formed in darkness fits the same regression as that shown in the Figure 1 inset or not and to elucidate if, consequently, this $\mathrm{A}+\mathrm{Z}$ plays the same role as $\mathrm{A}+\mathrm{Z}$ formed under light. As shown in Figure 7, irrespective of the treatment, the de-epoxidation of $\mathrm{V}$ was highly correlated with $\mathrm{Fv} / \mathrm{Fm}$ in thalli of $P$. canaliculata (Pearson's correlation coefficient; $r=0.906$; and $r=0.855$ when data from the high-temperature treatment were included). In 


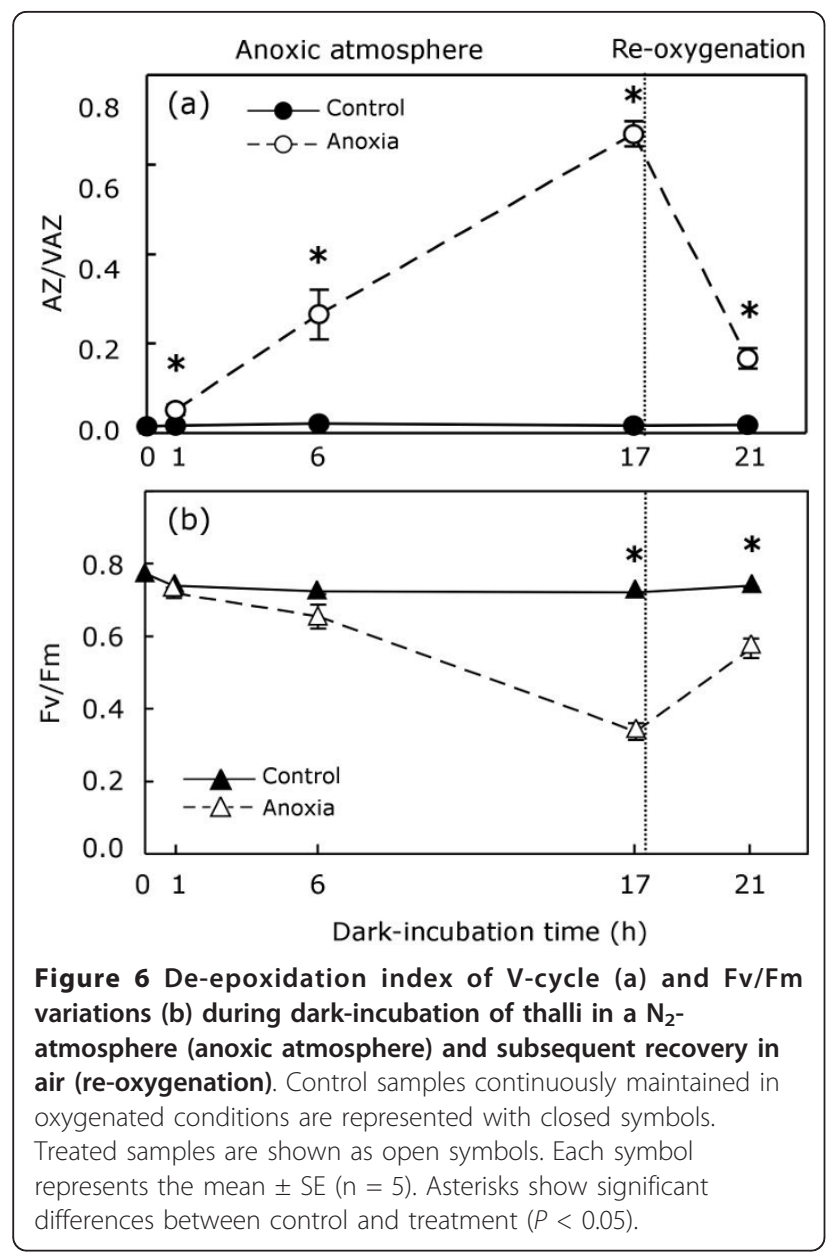

addition, there was a strong relationship between AZ/ $\mathrm{VAZ}$ and $\mathrm{Fv} / \mathrm{Fm}$ (Figure 7; linear regression model, $r^{2}=$ $0.833, P<0.001$; and $r^{2}=0.731, P<0.01$ when data from the high temperature treatment were included).

\section{Unravelling the common mechanism of V-cycle activation in darkness}

Trying to look more deeply into the biochemical mechanism that triggers the de-epoxidation of $\mathrm{V}$ in darkness upon such different stresses, three groups of inhibitors were employed. The first (DTT and SA) affected $\mathrm{V}$-cycle enzymes, the second $\left(\mathrm{NH}_{4} \mathrm{Cl}\right)$ uncoupled the transthylakoidal $-\Delta \mathrm{pH}$ and the third ( $\mathrm{n}$ PG, DCMU, DBMIB and FR) altered the redox state of the plastoquinone-pool (PQ-pool). The effect of these inhibitors on the AZ/VAZ was tested in thalli of $P$. canalicualta desiccated in darkness. The DTT brought about a complete inhibition of $\mathrm{Z}$ formation during desiccation (Figure 8). The SA, by contrast, led to a strong increase in $\mathrm{Z}$ accumulation in darkness. Although after desiccation, the SA-treated samples showed a AZ/ VAZ level 30\% higher than in the controls (Figure 8),

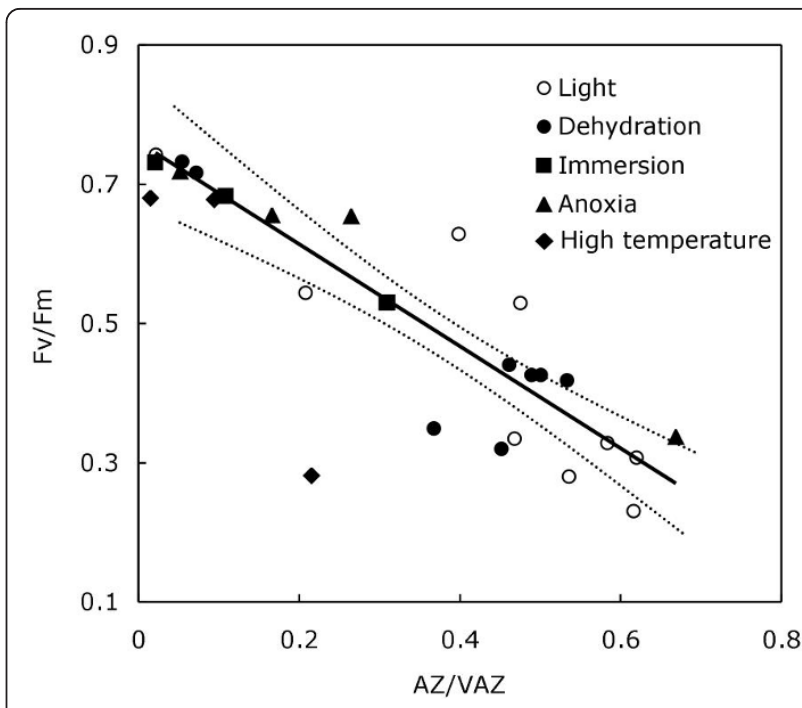

Figure 7 The relationship of AZ/VAZ and Fv/Fm in Pelvetia canaliculata. The data from the different experiments in this work are included: sun light exposition (open circles), dark-dehydration (close circles), dark-immersion (close squares), dark-incubation in anoxia (close triangles), dark-incubation at high temperature (close diamonds). Each point represents the mean $(n=5)$. The fit $\left(r^{2}=\right.$ 0.833) to a linear regression model (solid line) and the $95 \%$ confidence intervals (dashed lines) are presented (regression is significant at $P<0.001$ ). Although showed in the figure, data from the high temperature-treatment were excluded for the regression analysis since it induced irreversible damage on thalli.

the effect of SA was specially noticeable in hydrated samples in which the AZ/VAZ resulted more than 200fold higher than in hydrated controls $(0.921 \pm 0.026$ compared to $0.020 \pm 0.011$ ). Contrasting with this, the uncoupling of the transthylakoidal $-\Delta \mathrm{pH}$ by $\mathrm{NH}_{4} \mathrm{Cl}$ did not induce any significant change on the AZ/VAZ (Figure 8).

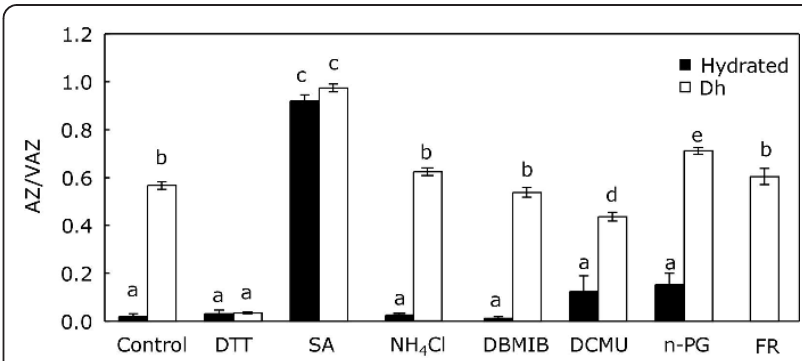

Figure 8 Effects of V-cycle inhibitors (DTT and SA), transthylakoidal- $\Delta \mathrm{pH}$ uncoupler $\left(\mathrm{NH}_{4} \mathrm{Cl}\right)$ and agents involved in the redox state of PQ (DBMIB, DCMU, n-PG, FR) on the deepoxidation of $\mathbf{V}$ during dehydration in darkness. Hydrated samples incubated at 100\% RH are represented by close bars. The AZ/ VAZ after dehydration in darkness is represented by open bars. Each bar represents the mean $\pm S E(n=5)$. Letters above bars indicate significant differences for AZNAZ among treatments $(P<0.05)$. 
The third group of inhibitors, acting over the redox state of the PQ pool, had no effect on the hydrated samples and little or no effect on the AZ/VAZ level reached after desiccation (Figure 8). Specifically, when compared with desiccated controls far red (FR) and DBMIB had no effect, DCMU induced a slight decrease and n-PG induced a slight increase on the AZ/VAZ level reached after dehydration.

\section{Discussion}

Photosynthetic organisms living in the intertidal zone need to be able to withstand sudden changes in their environmental factors (such as temperature, salinity, light and desiccation) associated with alternating periods of emergence and submergence. In fact, on rocky shores, seaweed species grow in differentiated horizontal belts characterised by specific levels of light and temperature stresses [29]. Light, influenced not only by the daily course of solar irradiance but also by the tidal range, is one of the most variable and limiting factors for intertidal species. Consequently, seaweeds have developed a set of photoprotective mechanisms that allow them to adjust the amount of light absorbed by their photosynthetic apparatus, thus optimizing its use when light limits photosynthesis, and developing fast photoprotective responses under the effect of photoinhibitory light intensities. Algae possess different photoprotective mechanisms, such as the adjustment of chloroplast orientation [30]; repair mechanisms [31]; the accumulation of UV-absorbing phenolic compounds [32]; or the xanthophyll cycles-related dissipation of the excess of absorbed light energy. The last of these mechanisms is the more flexible and rapid, being crucial for the prevention of photoinhibitory damage. In $P$. canaliculata, the Vcycle pool size is considerably higher than in other brown algae, as corresponds to its position in the uppermost intertidal belt [20]. In addition, it has been demonstrated that this species develops high, non-photochemical quenching (NPQ) when exposed to high irradiance [20]. As shown in Figure 1, light-induced de-epoxidation reverted after the onset of darkness, confirming the complete operation of the $\mathrm{V}$-cycle in this species.

García-Mendoza and Colombo-Pallota [13], have recently described that the brown alga Macrocystis pyrifera lacks the initial quenching of fluorescence shown for vascular plants [2], which is associated with the transthylakoidal- $\Delta \mathrm{pH}$. As a result, this species shows a direct and linear relationship between the $\mathrm{V}$-cycle de-epoxidation ratio and the NPQ, which does not occur in vascular plants in which the initial NPQ component (qE) is developed due to the $\Delta \mathrm{pH}$, independently of $\mathrm{V}$-cycle de-epoxidation. Similarly, a linear negative correlation was found between AZ/VAZ and Fv/Fm (Figure 1, inset), which implies a decrease in photochemical efficiency, mainly dependent on the V-cycle operation.
As previously demonstrated for other phototrophs, such as ferns and chlorolichens [11,12], in P. canaliculata the V-cycle operation can be induced solely by dehydration, independently of light (Figure 2). Furthermore, dehydration triggered the de-epoxidation of $\mathrm{V}$ and the down-regulation of $\mathrm{Fv} / \mathrm{Fm}$ to the same extent as illumination did (Figures 1 and 2). To clarify the similarities between light- and dehydration-induced V-cycle activities, a separate experiment was performed in which each branch of the same thalli were either exposed to light or kept in darkness, and subsequently dehydrated in darkness (thereby generating a branch in which $\mathrm{A}+\mathrm{Z}$ formation was triggered by light and another branch in which this formation was induced by dehydration). As shown in Figure 3, Fv/Fm decreased to the same extent irrespective of the origin of $\mathrm{V}$ de-epoxidation, suggesting that $\mathrm{A}+\mathrm{Z}$ play the same regulatory role when their formation is induced either by light or by dehydration.

Emersion frequently favours overheating, which damages temperate algae [18]. When Pelvetia thalli were exposed to $32^{\circ} \mathrm{C}$, the heat treatment induced an increase in $\mathrm{A}+\mathrm{Z}$ but the $\mathrm{AZ/VAZ}$ reached was lower than that reached after any other treatment, i.e., dehydration (Figure 2 ), immersion (Figure 5), or anoxia (Figure 6). The decrease in $\mathrm{Fv} / \mathrm{Fm}$ was notably larger than that observed for the same level of de-epoxidation in other treatments (note the outlayer point in Figure 7). Besides, the decrease in $\mathrm{Fv} / \mathrm{Fm}$ and the increase in $\mathrm{AZ} / \mathrm{VAZ}$ were not reversible after treatment had ceased, indicating that the stress was probably beyond the lethal threshold for a cool water macroalga. Indeed, for other species it has been recently shown that moderate heat stress can affect thylakoid reactions greatly [33].

Besides desiccation and high temperature, periodic hypoxic episodes in intertidal pools may be detrimental for the photosynthetic organisms of those habitats $[34,35]$, especially at night (when no photosynthetic production of oxygen can counteract respiration). Astonishingly, immersion (Figure 5) or anoxia followed by reoxygenation in an absence of light (Figure 6), induced the same effects on the V-cycle and Fv/Fm as did dehydration-rehydration or light-darkness cycles. The activation of VDE by immersion may be due to the cellular acidification induced by the release of respiratory $\mathrm{CO}_{2}$, or by fermentative metabolism [36], but this hypothesis seems unlikely because of the intrathylakoidal location of this enzyme.

Considering the unlikelihood of that hypothesis, the acidification of lumen due to chlororespiration would become a mechanism to take into account. Essentially, during chlororespiration, the plastid terminal oxidase (PTOX) may oxidize plastoquinol $\left(\mathrm{PQH}_{2}\right)$ by transferring electrons to oxygen [37] and at the same time, the pumping of protons towards the lumen would take place [38], 
providing the lumenal acidic $\mathrm{pH}$ required for the VDE activation. Several authors have described the activation of the chlororespiratory pathway by anoxia $[39,40]$. Although the accumulation of de-epoxidized xanthophylls under chlororespiratory conditions was never observed in green algae [41], chlororespiration has been recently proposed as the mechanism responsible for the dark activation of the diadinoxanthin cycle in diatoms under anoxic conditions [40]. Apart from anoxia, Brüggemann and co-workers have recently proposed chlororespiration as the mechanism responsible for the AZ/VAZ increase observed during the dark incubation of some winter-acclimated oaks at room temperature [10]. Both these examples suggest that chlororespiration may represent a plausible explanation for the activation of $\mathrm{V}$ deepoxidation showed by $P$. canaliculata in darkness. This may be the case of desiccating or overheated tissues, but under anoxia, it is unlikely that PTOX would be able to oxidize $\mathrm{PQH}_{2}$ due to the absence of the electron acceptor (oxygen), even when it is considered that under these conditions the PQ pool should be over-reduced [42]. Furthermore, the inhibition of PTOX by n-PG did not block the de-epoxidation of $\mathrm{V}$-cycle pigments that occurred in darkness during desiccation (Figure 8). This result indicates that another mechanism, other than the PTOX-mediated oxidation of $\mathrm{PQ}$, may be responsible for the generation of the transthylakoidal- $\Delta \mathrm{pH}$ needed for the VDE activation. Nevertheless, the fact that $\mathrm{Z}$ accumulation during desiccation of samples in darkness was unaltered by the application of the uncoupler $\mathrm{NH}_{4} \mathrm{Cl}$ (Figure 8) led us to consider an alternative explanation for the de-epoxidation of $\mathrm{V}$ in darkness.

It is sometimes thought that under strong light conditions only VDE is activated whereas only ZE works at night or under low light conditions. Nevertheless, ZE activity seems to be constitutive [43]. The complete deepoxidation of $\mathrm{V}$ induced in darkness by SA (Figure 8), together with the inhibition of $\mathrm{V}$ de-epoxidation induced by DTT, suggests that also VDE activity is constitutive, even in darkness. In the absence of light, $\mathrm{Z}$ accumulation is not observed under non-stressful conditions because ZE prevents its accumulation. However, the inhibition of $\mathrm{ZE}$ induced by stress would lead to the de-epoxidation of most of $\mathrm{V}$, and to the consequent increase in the protective $\mathrm{Z}$. Since $\mathrm{ZE}$ requires molecular oxygen as second substrate an NADPH as cofactor, both molecules may limit the ZE activity [43]. The underlying mechanism responsible for such inhibition is unknown, but it may be associated with the availability of NADPH, as has been shown in Arabidopsis mutants lacking a chloroplastic NAD Kinase [9]. In these mutants, ZE reduces its activity due to the reduced availability of its cofactor NADPH. Consequently, these plants accumulate high amounts of $\mathrm{Z}$ even in low light [9].

\section{Conclusions}

In this study it has been shown that, irrespective of the nature of the factor inducing $\mathrm{V}$ de-epoxidation, resultant $\mathrm{A}+\mathrm{Z}$ molecules always contribute to the down-regulation of photochemical efficiency. In fact, when AZ/VAZ values against $\mathrm{Fv} / \mathrm{Fm}$ for all the experiments reported here were plotted in the same regression, a significant linear dependence was observed between them, irrespective of the stress factor (Figure 7). This observation provides a physiological meaning for the reported dark activation of the $\mathrm{V}$-cycle, but also opens the question about the role and adaptive values of this trait. All the experimental evidence [4] supports the theory that VDE activation requires an acidic $\mathrm{pH}$, which is typically generated by light-induced proton pumping, but the dark accumulation of $Z$ requires a different explanation, probably associated with the down-regulation of $\mathrm{ZE}$ activity. Although the molecular basis of ZE down-regulation remains unclear, there is some evidence that phosphorylation reactions might be involved in this $[22,44,45]$.

Considering the emerging number of stressors that lead to $\mathrm{Z}$ formation in darkness, and the multiple protective roles of this xanthophyll in membrane stabilization $[46,47]$, in the prevention of the reactive oxygen species (ROS) generation $[48,49]$ and in the scavenging of ROS [50], it seems that, more than being a biochemical curiosity, $\mathrm{V}$ de-epoxidation in darkness must represent a very important and finely-regulated protective mechanism. The wide occurrence of $\mathrm{V}$-cycle activity in darkness in terms of phylogenetic groups [51] and in terms of inducing factors (as shown in this work) may imply that this is a common response to most stressors that has been conserved tenaciously during the evolution, to protect thylakoid membranes and photosynthetic machinery under hazardous conditions even when these occur in the dark.

\section{Abbreviations}

A: antheraxanthin; DBMIB: Dibromo isopropyl methyl benzoquinone; DCMU: Dichlorophenyl dimethylurea; DTT: dithiothreitol; Fv/Fm: maximal photochemical efficiency of the PS $\|_{;}$HT: high temperature; NPQ: nonphotochemical quenching; n-PG: n-propyl-gallate; PTOX: plastid terminal oxidase; R: rehydration; $\mathrm{RH}$ : relative humidity; $\mathrm{SA}$ : salicyl-adoxime; V: violaxanthin; V-cycle: violaxanthin cycle; VDE: Violaxanthin de-epoxidase; Z: zeaxanthin.

\section{Acknowledgements}

This work was supported by the Spanish Ministry of Education and Science [BFU 2010-15021] and by the Basque Government [UPV/EHU-GV IT-299-07]. BFM received a fellowship from the Basque Government.We thank Brian Webster for english revision.

\section{Authors' contributions}

BFM and JIGP designed and performed the experiments. FM and BFM carried out the HPLC analyses. JIGP, BFM and FM analyzed fluorescence. JMB BFM and JIGP performed the experiments with inhibitors and the statistical analysis. All authors read and approved the final version of the manuscript. 
Received: 9 July 2011 Accepted: 26 December 2011

Published: 26 December 2011

\section{References}

1. Saga G, Giorgietti A, Fufezan C, Giacometti GM, Bassi R, Morosinotto T: Mutation analysis of violaxanthin de-epoxidase identifies substratebinding sites and residues involved in catalysis. J Biological Chemistry 2010, 285:23763-23770.

2. Müller $P$, Li XP, Niyogi KK: Non-Photochemical quenching. A response to escess light energy. Plant Physiol 2001, 125:1558-1566.

3. Holt NE, Zigmantas D, Valkunas L, Li XP, Niyogi KK, Fleming GR: Carotenoid cation formation and the regulation of photosynthetic light harvesting. Science 2005, 307:433-436.

4. Ruban AV, Berera R, llioaia C, van Stokkum IHM, Kennis JTM, Pascal AA, van Amerongen $\mathrm{H}$, Robert $\mathrm{B}$, Horton $\mathrm{P}$, van Grondelle R: Identification of a mechanism of photoprotective energy dissipation in higher plants. Nature 2007, 450:575-578.

5. Ahn TK, Avenson TJ, Ballottari M, Cheng YC, Niyogi KK, Bassi R, Fleming GR: Architecture of a charge-transfer state regulating light harvesting in a plant antenna protein. Science 2008, 320:794-797.

6. Holzwarth AR, Miloslavina Y, Nilkens M, Jahns P: Identification of two quenching sites active in the regulation of photosynthetic light-harvesting studied by time-resolved fluorescence. Chem Phys Lett 2009, 483:262-267.

7. Müller M, Lambrev P, Reus M, Wientjes E, Croce R, Holzwarth AR: Singlet energy dissipation in photosystem II light-harvesting complex does not involve energy transfer to carotenoids. Chem Phys Lett 2010, 11:1289-1296.

8. Gilmore AM, Yamamoto HY: Dark induction of zeaxanthin dependent nonphotochemical fluorescence quenching mediated by ATP. Proc Natl Acad Sci USA 1992, 89:1899-1903.

9. Takahasi H, Watanabe A, Tanaka A, Hashida S, Kawai-Yamada M, Sonoike K, Uchimiya H: Chloroplast NAD Kinase is essential for energy transduction through the xanthophyll cycle in photosynthesis. Plant Cell Physiol 2006, 47:1678-1682.

10. Brüggemann W, Bergmann $M$, Nierbauer KU, Pflug E, Schmidt C, Weber C: Photosynthesis studies on European evergreen and deciduous oaks grown under Central European conditions: II. Photoinhibitory and lightindependent violaxanthin de-epoxidation and down regulation of photosystem II in evergreen, winter-acclimated European Quercus taxa. Trees 2009, 23:1091-1100.

11. Fernández-Marín B, Balaguer L, Esteban R, Becerril JM, García-Plazaola J: Dark induction of the photoprotective xanthophyll cycle in response to dehydration. J Plant Physiol 2009, 166:1734-1744

12. Fernández-Marín B, Becerril JM, García-Plazaola Jl: Unravelling the roles of desiccation-induced xanthophyll cycle activity in darkness: a case study in Lobaria pulmonaria. Planta 2010, 231:1335-1342.

13. García-Mendoza E, Colombo-Pallotta MF: The giant kelp Macrocystis pyrifera presents a different nonphotochemical quenching control than higher plants. New Phytol 2007, 173:526-536.

14. Pogson BJ, Niyogi KK, Della-Pena D: Altered xanthophylls composition adversely affects chlorophyll accumulation and non-photochemical quenching in Arabidopsis mutants. Proc Nat Acad Sci USA 1998, 95:13324-13329.

15. Pfetzing J, Stengel DB, Cuffe MM, Savage AV, Guiry MD: Effects of temperature and prolonged emersion on photosynthesis, carbohydrate content and growth of the brown intertidal alga Pelvetia canaliculata. Botanica Marina 2000, 43:399-407.

16. Schonbeck MW, Norton TA: Drought-hardening in the upper limits of fucoid algae on the shore. J Ecol 1979, 67:687-696.

17. Hudson HJ: Fungal Biology Cambridge: Cambridge University Press; 1992

18. Collén J, Davison IR: Stress tolerance and reactive oxygen metabolism in the intertidal red seaweeds Mastocarpus stellatus and Chondrus crispus. Plant Cell Environ 1999, 22:1143-1151.

19. Hupel M, Lecointre C, Meudec A, Poupart N, Gall EA: Comparison of photoprotective responses to UV radiation in the brown seaweed Pelvetia canaliculata and the marine angiosperm Salicornia ramosissima. J Exp Marine Biol Ecol 2011, 401:36-47.

20. Harker M, Berkaloff $C$, Lemoine $Y$, Britton G, Young AJ, Duval JC, Rmiki NE, Rousseau B: Effects of high light and desiccation on the operation of the xanthophyll cycle in two marine brown algae. Europ J Phycol 1999, 34:35-42.
21. Yamamoto HY, Komite $L$ : The effects of dithiothreitol on violaxanthin deepoxidation and absorbance changes in the 500-nm region. Biochim Biophys Acta 1972, 267:538-543.

22. Xu CC, Jeon YA, Hwang HJ, Lee $\mathrm{CH}$ : Suppression of zeaxanthin epoxidation by chloroplast phosphatase inhibitors in rice leaves. Plant Sci 1999, 146:27-34.

23. Roberts $A G$, Kramer DM: Inhibitor "Double occupancy" in the $Q_{0}$ pocket of the chloroplast cytochrome b6f complex. Biochem 2001, 40:13407-13412.

24. Graan T: Evidence for a dual function of the herbicide-binding D1protein in photosystem-II. FEBS Letters 1986, 205:296-274.

25. Josse EM, Alcaraz JP, Labouré AM, Kuntz M: In vivo characterization of a plastid terminal oxidase (PTOX). Europ J Biochem 2003, 270:3787-3794.

26. Nedbal L, Soukupova J, Kaftan D, Whitmarsh J, Trtilek M: Kinetic imaging of chlorophyll fluorescence using modulated light. Photosynth Res 2000, 66:3-12.

27. García-Plazaola Jl, Becerril JM: A rapid HPLC method to measure lipophilic antioxidants in stressed plants: simultaneous determination of carotenoids and tocopherols. Phytochem Anal 1999, 10:307-313.

28. García-Plazaola JI, Becerril JM: Seasonal changes in photosynthetic pigments and antioxidants in beech (Fagus sylvatica) in a Mediterranean climate: implications for tree decline diagnosis. Aust J Plant Physiol 2001, 2:225-32.

29. Rodrigues MA, Santos CPD, Yoneshigue-Valentin Y, Strbac D, Hall DO: Photosynthetic light response curves and photoinhibition of the deep water Laminaria abyssalis and the intertidal Laminaria digitata (Phaeophyceae). J Phycol 2000, 36:97-106.

30. Nultsch W, Pfau J, Rüffer U: Do correlation exist between chromatophore arrangement and photosynthetic activity in seaweeds? Marine Biol 1981, 62:111-117.

31. Häder DP, Lebert M, Sinha RP, Barbieri ES, Helbling EW: Role of protective repair mechanisms in the inhibition of photosynthesis in marine macroalgae. Photochem Photobio/ Sci 2002, 1:809-814.

32. Connan S, Deslandes E, Gall EA: Influence of day-night and tidal cycles on phenol content and antioxidant capacity in three temperate intertidal brown seaweeds. J Exp Marine Biol Ecol 2007, 349:359-369.

33. Zhang R, Cruz JA, Kramer DM, Magallanes-Lundback ME, DellaPenna D, Sharkey TD: Moderate heat stress reduces the $\mathrm{pH}$ component of the transthylakoid proton motive force in light-adapted, intact tobacco leaves. Plant Cell Environ 2009, 32:1538-1547.

34. Peckol P, Rivers JS: Physiological responses of the opportunistic macroalgae Cladophora vagabunda (L.) van den Hoek and Gracilaria tikvahiae (McLachlan) to environmental disturbances associated with eutrophication. J Exp Marine Biol Ecol 1995, 190:1-16.

35. Pulido C, Borum J: Eelgrass (Zostera marina) tolerance to anoxia. J Exp Marine Biol Ecol 2010, 385:8-13.

36. Summers JE, Ratcliffe RG, Jackson MB: Anoxia tolerance in the aquatic monocot Potamogeton pectinatus: absence of oxygen stimulates elongation in association with an unusually large Pasteur effect. J Exp Bot 2000, 51:1413-1422.

37. Peltier G, Cournac L: Chlororespiration. Annu Rev Plant Biol 2002, 53:523-550.

38. Rumeau D, Peltier G, Cournac L: Chlororespiration and cyclic electron flow around PSI during photosynthesis and plant stress response. Plant Cell Environ 2007, 30:1041-1051.

39. Haldimann P, Strasser RJ: Effects of anaerobiosis as probed by the polyphasic chlorophyll a fluorescence rise kinetic in pea (Pisum sativum L.). Photosynth Res 1999, 62:67-83.

40. Cruz S, Goss R, Wilhelm C, Leegood R, Horton P, Jakob T: Impact of chlororespiration on non-photochemical quenching of chlorophyll fluorescence and on the regulation of the diadinoxanthin cycle in the diatom Thalassiosira pseudonana. J Exp Bot 2010, 62:509-519.

41. Goss R, Jakob T: Regulation and function of xanthophyll cycle-dependent photoprotection in algae. Photosynth Res 2010, 106:103-122.

42. Wright AH, DeLong JM, Gunawardena A, Prange RK: The interrelationship between the lower oxygen limit, chlorophyll fluorescence and the xanthophyll cycle in plants. Photosynth Res 2011, 107:223-235.

43. Jahns $P$, Latowski D, Strzalka K: Mechanism and regulation of the violaxanthin cycle: the role of antenna proteins and membrane lipids. Biochim Biophys Acta 2009, 1787:3-14.

44. Ebbert V, Adams WW, Mattoo AK, Sokolenko B, Demmig-Adams B: Upregulation of a photosystem II core protein phophatase inhibitor and 
sustained D1 phophorylation in zeaxanthin-retaining, photoinhibited needles of overwintering Douglas fir. Plant Cell Environ 2005, 28:232-240

45. Rokka A, Aro EM, Herrmann RR, Andersson B, Vener AV: Dephosphorylation of photosystem II reaction center proteins in plant photosynthetic membranes as an immediate response to abrupt elevation of temperature. Plant Physiol 2000, 123:1525-1535.

46. Havaux M: Carotenoids as membrane stabilizers in chloroplasts. Trends Plant Sci 1998, 3:147-151.

47. Kostecka-Gugala A, Latowski D, Strzalka K: Thermotropic phase behaviour of alpha-dipalmitoylphosphatidylcholine multibilayers is influenced to various extents by carotenoids containing different structural featuresevidence from differential scanning calorimetry. Biochem Biophys Acta 2003, 1609:193-202.

48. Ruban AV, Johnson MP: Xanthophylls as modulators of membrane protein function. Arch Biochem Biophys 2010, 504:78-85.

49. Betterle N, Ballottari M, Hienerwadel R, Dall'Osto L, Bassi R: Dynamics of zeaxanthin binding to the Photosystem II monomeric antenna protein Lhcb6 (CP24) and modulation of its photoprotection properties. A Biochim Biophys 2010, 504:67-77.

50. Havaux M, Dall'Osto L, Bassi R: Zeaxanthin has enhanced antioxidant capacity with respect to all other xanthophylls in Arabidopsis leaves and functions independent of binding to PS II antennae. Plant Physiol 2007, 145:1506-1520.

51. Fernandez-Marín B, Míguez F, Becerril JM, García-Plazaola J: Dehydrationmediated activation of the xanthophyll cycle in darkness: is it related to desiccation tolerance? Planta 2011, doi: 10.1007/s00425-011-1420-1.

doi:10.1186/1471-2229-11-181

Cite this article as: Fernández-Marín et al: Activation of violaxanthin cycle in darkness is a common response to different abiotic stresses: a case study in Pelvetia canaliculata. BMC Plant Biology 2011 11:181.

\section{Submit your next manuscript to BioMed Central and take full advantage of:}

- Convenient online submission

- Thorough peer review

- No space constraints or color figure charges

- Immediate publication on acceptance

- Inclusion in PubMed, CAS, Scopus and Google Scholar

- Research which is freely available for redistribution

Submit your manuscript at www.biomedcentral.com/submit
Biomed Central 